\title{
Counseling of behavior healthy life in Purba Horison Village, Haranggaol District, Simalungun Regency, North Sumatra Province towards the industrial revolution 4.0
}

\author{
Bina Melvia Girsang ${ }^{1 *}$, Rikki Simanullang ${ }^{2}$, Kusnadi $^{2}$, Haryati Asri Ningrum ${ }^{2}$, Sri Aulia \\ Pratiwi $^{2}$ \\ ${ }^{1}$ Faculty of nursing, Universitas Sumatera Utara \\ ${ }^{2}$ Student of KKN, Universitas Sumatera Utara \\ *Email: binamelvia@usu.ac.id
}

\begin{abstract}
Clean and Healthy Life Behavior (PHBS) is one way for the community to be able to maintain the quality of their health. In PHBS there are several indicators that are used as a reference in the implementation of PHBS, one of them washing hands with soap. Good clean and healthy behavior can prevent diseases that appear in the body. Based on the activities carried out by the 2019 KKN Student in Purba Horison Village, Haranggaol District, Simalungun Regency, North Sumatra Province, several problems in the Purba Horison Village have been resolved, namely the lack of public knowledge in the use and utilization of the potential of Natural Resources in the Village Purba Horizon, lack of public knowledge to produce a creative economy, the lack of community care Purba Horizon Village towards environmental cleanliness. With the existence of a clean and healthy life style, this will affect the health status of the community, especially the people of the Village of Horizon, who will be conducted a real work lecture as a form of activities carried out by students.
\end{abstract}

\section{Keywords: PHBS, health}

\begin{abstract}
Abstrak
Perilaku Hidup Bersih dan Sehat (PHBS) merupakan salah satu cara masyarakat untuk dapat menjaga kualitas kesehatannya. Dalam PHBS terdapat beberapa indikator yang dijadikan acuan dalam pelaksanaan PHBS salah satunya cuci tangan pakai sabun. Perilaku hidup bersih dan sehat yang baik dapat mencegah terjadinya penyakit yang muncul dalam tubuh. Berdasarkan kegiatan yang telah dilakukan oleh Mahasiswa KKN Bersama 2019 Desa Purba Horison, Kecamatan Haranggaol, Kabupaten Simalungun, Provinsi Sumatera Utara beberapa permasalahan di Desa Purba Horison yang telah dapat diselesaikan, yaitu minimnya pengetahuan masyarakat dalam penggunaan dan pemanfaatan potensi Sumber Daya Alam yang ada di Desa Purba Horison, minimnya pengetahuan masyarakat untuk menghasilkan ekonomi kreatif, kurangnya peduli masyarakat Desa Purba Horison terhadap kebersihan lingkungan. Dengan adanya perilaku hidup bersih dan sehat ini akan mempengaruhi derajat kesehatan pada masyarakat terkhusus pada masyarakat DesaPurba Horison yang akan dilakukan kuliah kerja nyata sebagai bentuk kegiatan yang dilaksanakan oleh mahasiswa.
\end{abstract}

Kata Kunci: PHBS, kesehatan

\section{PENDAHULUAN}

Kuliah Kerja Nyata (KKN) merupakan perwujudan dari salah satu Tridarma Perguruan Tinggi, yakni pendidikan dan pengajaran yang memiliki nilai penting dalam Tridarma Perguruan Tinggi, pendidikan dan pengajaran ini merupakan proses pembelajaran untuk menciptakan generasi unggul dari suatu perguruan tinggi yang akan membawa bangsa ini ke arah yang lebih maju. Penelitian dan pengembangan juga sangat penting bagi kemajuan bangsa dan negara. Dari penelitian dan pengabdiana ini mahasiswa mampu mengembangkan ilmu dan teknologi, yang harus cerdas, 
kreatif dan kritis dalam menjalankan perannya sebagai agent of change. Pengabdian kepada masyarakat yang merupakan kegiatan positif dan bersifat lintas disiplin (interdispliner) serta komponen keilmuan, teknologi, dan seni secara aplikatif guna membantu kehidupan masyarakat, utamanya dipedesaan. Pelaksaan KKN diharapkan para mahasiswa dapat membantu menghadapi kesulitan-kesulitan yang dihadapi sesuai dengan bidang keilmuan masing-masing. Melalui KKN ini pula mahasiswa dapat membantu merealisasikan program-program pemerintah dalam rangka melaksanakan pemerataan pembangunan di desa.

Universitas Sumatera Utara selaku lembaga pendidikan yang mempunyai kewajiban melaksanakan Tridarma perguruan tinggi yaitu salah satunya dengan mengadakan KKN. Atas dasar itulah maka kami kelompok mahasiswa KKN Bersama BKS-PTN Barat yang ditempatkan di desa Purba Horison Kecamatan Haranggaol Kabupaten Simalungun berkewajiban bersama-sama dengan warga desa guna merealisasikan substansi dari KKN tersebut sesuai dengan judul KKN Bersama yaitu " Bersama Memberdayakan Kearifan Lokal dan Ekowisata Menuju Revolusi Industri 4.0".

Hal ini ditujukan untuk membantu memperbaiki sarana dan prasarana dasar beserta meningkatkan sumber daya manusia yang ada di Desa Purba Horison agar kearifan lokal dan ekowisata yang lebih berkualitas serta membantu masyarakat lokal menjaga sumber daya alam agar lestari.

\section{METODE PELAKSANAAN}

\subsection{Waktu Pelaksanaan}

Kegiatan kuliah kerja nyata yang dilakukan oleh mahasiswa ini dilaksanakan sesuai dengan kegiatan KKN yang tertuang dalam Kalender Akademik yaitu mulai tanggal 15 Juli 2019 sampai 19 Agustus 2019.

\subsection{Sasaran}

Sasaran kegiatan KKN ini adalah masyarakat Desa Purba Horison, Kecamatan Haranggaol Horison, Kabupaten Simalungun, Provinsi Sumatera Utara sebagai lokasi kegiatan KKN Bersama mahasiswa dari 20 PTN BKS Barat. Metode pelaksanaan berisi metode-metode pelaksanaan yang sesuai teori dari buku ataupun artikel yang disitasi. Sitasi dilarang menggunakan akses dari sebuah website. Metode dituliskan secara rinci dan jelas. Jika perlu bisa digambarkan diagram alir untuk metode pelaksanaan sama dengan aturan untuk membuat diagram alir dari suatu algoritma.

\section{HASIL DAN PEMBAHASAN}

\subsection{Sasaran}

Dalam menunjang keberlangsungan kegiatan pada umumnya terlebih kuliah kerja nyata pada khususnya, maka diperlukan sasaran kegiatan. Sasaran yang dibutuhkan dalam kegiatan ini, yaitu:

1. Masyarakat Purba Horison

2. Anak SD Purba Horison

\subsection{Maksud danTujuan}

Adapun maksud dan tujuan dari kegiatan yang dilakukan di Desa Purba Horison, yaitu: 
1. Untuk mengajarkan tentang perilaku hidup bersih dan sehat pada masyarakat dan anak sekolah dasar

2. Untuk menginformasikan pentingnya ber- perilaku hidup bersih dan sehat dalam kehidupan sehari-hari

3. Menanamkan perilaku hidup bersih dan sehat pada masyarakat dan anak sekolah dasar untuk meningkatkan derajat kesehatan masyarakat.

\subsection{Manfaat Kegiatan}

Manfaat kegiatan yang dilakukan di Desa Purba Horison, yaitu:

1. Masyarakat mengetahui pengertian, manfaat dan tujuan dalam pelaksaan PHBS

2. Meningkatnya derajat kesehatan masyarakat

\subsection{Tempat / Lokasi Kegiatan}

Tempat dan lokasi yang menjadi target dalam kegiatan yang dilakukan di Desa Purba Horison, yaitu:
1. SD Negeri 091371 Bangun Purba
2. SD Negeri 091353 Halaotan
3. Masyarakat Dusun Silumbak ( Dusun I )
4. Masyarakat Dusun Bangun Purba ( Dusun II )
5. Masyarakat Dusun Liang Nakka ( Dusun III )
6. Masyarakat Dusun Halaotan ( Dusun IV )

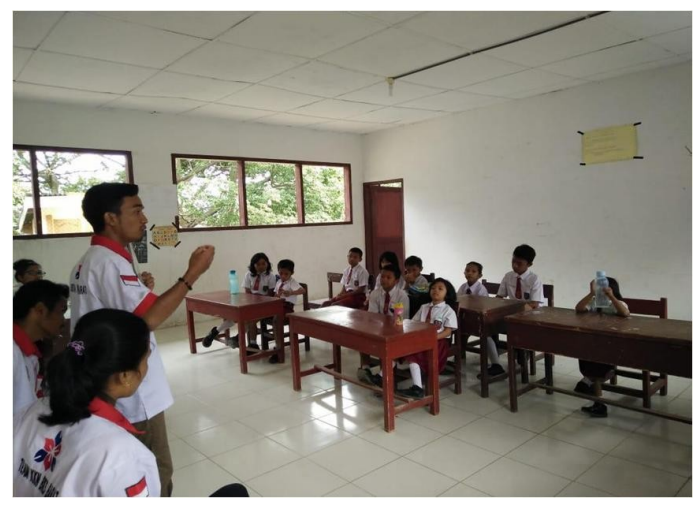

Gambar 3.1 Penyuluhan pada tingkat SD mengenai perilaku hidup bersih dan sehat
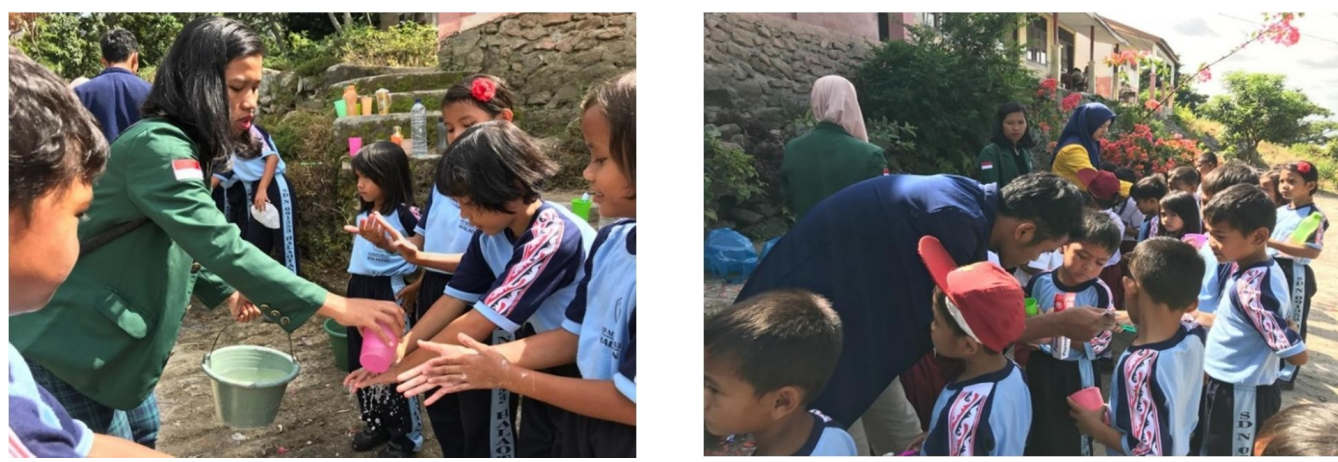

Gambar 3.2. Praktik mengenai kegiatan yang dilakukan terhadap perilaku hidup bersih dan sehat 
Kegiatan yang dilakukan terhadap sekolah berjalan dengan baik dimaksudkan untuk menjadi dasar pengetahuan bagi anak - anak dalam mengubah pola hidup menjadi lebih baik yang berdampak positif bagi diri sendiri. Perilaku hidup bersih dan sehat yang baik dan dilakukan di setiap kegiatannya akan menanamkan perilaku hidup bersih anak sekolah dasar untuk meningkatkan derajat kesehatan masyarakat.

\section{KESIMPULAN}

Berdasarkan kegiatan yang telah dilakukan oleh Mahasiswa KKN Bersama 2019 kelompok 16 Desa Purba Horison, Kecamatan Haranggaol, Kabupaten Simalungun, Provinsi Sumatera Utara dapat disimpulkan bahwa dengan antusiasnya masyarakat mengenai pola hidup bersih dan sehat maka akan meningkatkan kepedulian masyarakat Desa Purba Horison terhadap kebersihan lingkungan.

\section{UCAPAN TERIMAKASIH}

Peserta KKN Bersama Kelompok 16 mengucapkan terimakasih kepada berbagai pihak yang telah membantu kami dalam menyelesaikan kegiatan KKN ini. Ucapan terimakasih ini kami sampaikan kepada:

1. Prof. Tulus, Vor. DIPL., Math, M.Si., Ph.D selaku Ketua LPPM USU yang telah memberi kesempatan kepada kami terpilih sebagai peserta KKN Bersama.

2. Ibu Bina Melvia Girsang, S.Kep. Ns,M.Kep selaku dosen pembimbing lapangan kelompok 16 yang banyak memberi kami kritik, saran, bimbingan dan arahan selama pelaksanaan KKN.

3. Bapak Jr.saragih selaku Bupati Simalungun yang menerima penempatan KKN Bersama di Kabupaten Simalungun dan menyambut kedatangan para peserta KKN Bersama dengan sangat antusiasnya.

4. Bapak Ramasdi Saragih selaku Kepala Desa Purba Horison dan para perangkat desa yang menerima kami di Desa Purba Horison dengan sangat baik dan membuat kami nyaman dengan segala fasilitas yang diberikan.

5. Kepala sekolah SD SD Negeri 091371 Bangun dan SD Negeri 091353 Halaotan yang memberi kesempatan kepada kami untuk mengajarkan ilmu yang kami miliki serta membantu tenaga pengajar dalam mendidik para siswa/siswi yang sekolah di SD tersebut.

6. Kepada masyarakat Dusun Silumbak, masyarakat Dusun Bangun Purba, masyarakat Dusun Liang Nakka, masyarakat Dusun Halaotan yang membantu mensukseskan kegiatan KKN Bersama kami hingga selesai.Semua pihak yang membantu dalam pegabdian masyarakat maupun penelitian wajib dituliskan di bab ccapan terimakasih ini.

\section{DAFTAR PUSTAKA}

Alligood, M.R. \& Tomey, A.M. (2006). Nursing theory utilization dan application. (edisi 3). USA : Mosby elsevier.

Affonso, D. D., et al. (1989). Exploration of mother's reactions to the kangaroo method of prematurity care. Neonatal network, 7(6) : 43-51 dalam Dodd

V.L. (2003). Effects kangaroo care in preterm infants. University of Connecticut. http://www.proquest.umi.com diperoleh tanggal 15 Januari 2014

Anonymous. Kangaroo care. Diunduh dari http://en.wikipedia.org/wiki/kangaroo_care. tanggal 
20 Januari 2014

Anonymous. Principles of kangaroo mother care. Perinatal Education Programme. Mother and Baby Friendly Care: Unit 43-44:6/2004. Diakses tanggal 20 Januari 2014

A Randomized, Controlled Trial of Kangaroo Mother care : Result of Follow- Up at 1 Year of Correct Age. (2001). Journal of The American Academy of Pediatrics. 108(5): 1072-1079. Diambil dari http://www.pediatrics.aapublications.org/egi/reprint/108/5/1072 diakses tanggal 20 Januari 2014

Anderson., GC. (1989). Risk in mother-infant separation post birth. Image.21:196-199 Anisio Veloso, (2002). The Impact of Kangaroo Mother Care on Neonatal Mortality in Brazil. PAHO REPORT : Brazil 